\title{
Two-dimensional simulations of katabatic layers observed during the GIMEX experiment
}

\author{
A. Elkhalfi ${ }^{1^{*}}$ \\ ${ }^{1}$ Laboratoire d'Aérologie, URA CNRS 354, Université Paul Sabatier Toulouse France
}

Received: 7 July 1997 / Revised: 9 June 1998 / Accepted: 3 September 1998

\begin{abstract}
The hydrostatic model SALSA is used to simulate a particular event observed during the Greenland Ice Margin EXperiment "GIMEX" (on July 12th, 1991). The time evolution of the large-scale flow was incorporated in the model through time dependent boundary conditions which were updated using the closest upwind sounding. A turbulent scheme for the stable boundary layer and an appropriate parametrization of the surface fluxes implemented in the same model, are used for this study. The simulation results are discussed and compared to the available observations. The computed turbulent fluxes are correctly estimated. The model predicts a mixing zone of about $1500 \mathrm{~m}$ high which is in good agreement with tundra site observations. Over the ice cap, the katabatic layer is correctly simulated by the model. Its height of $80-300 \mathrm{~m}$ is well estimated. The comparison between the simulation and observations taken at ice cap sites is reasonably valid. The ablation computed along the ice cap corresponds well to the values reconstructed of observations at sites 4 and 9. Finally, a sensibility study to a specified westward geostrophic wind $\left(2 \mathrm{~ms}^{-1}\right)$ shows that the consideration of this latter improves the simulated tundra wind evolution.
\end{abstract}

Key words. Meteorology and atmospheric dynamics (mesoscale meteorology; polar meteorology; turbulance).

\section{Introduction}

katabatic winds are low layer winds resulting from the presence of a terrain slope effect together with a strong

\footnotetext{
*Present address: Laboratoire de Mécanique Faculté des Sciences et Techniques Route d'Immouzer, B.P. 2202, Fez Morocco Fax: (212) 5608214
}

temperature inversion near the surface. The generator mechanism for katabatic flows is the combined action of the gravity force and the Coriolis force. Katabatic flows are mainly observed in polar regions. They are an efficient means of redistributing energy in the atmosphere. They also contribute to breaking and dispersing the ice pack. These latter fluctuations modify the energy budget of the atmosphere by intensifying the heat exchange between the air and the free sea. Therefore, their influence on the local and planetary climate is thought important (Wendler et al., 1983).

A recent field program devoted to ablation measurements was the GIMEX experiment, which took place in southwestern Greenland during the summer of 1991. A number of numerical studies based upon the GIMEX data are currently being carried out. For example, Meesters et al. (1994) and Gallée et al. (1995) have simulated the GIMEX situations with a hydrostatic model developed particularly for katabatic flows.

The SALSA model, which is completely different from that of Meesters et al. (1994) and Gallée et al. (1995) is used for katabatic flow simulations. The differences with our investigation model concern the physics process, the turbulence closure scheme, the soil parametrization and the time evolution boundary conditions. The numerical model used here has been widely validated for mountain wave flows observed during the pyrenees Experiment (Georgelin et al., 1994; Elkhalfi et al., 1995) and for sea-breeze simulations (Bechtold et al., 1991). In the present study, emphasis is laid on the formation of the boundary layer exchange and its time evolution. For these reasons, a turbulent scheme of stably stratified atmosphere over the ice sheet and an appropriate parametrization of the surface have been developed. Another objective is to compute the ice melting based on a parametrization of the ablation process.

The SALSA model, which is an important tool for the interpretation of measurements, is adapted for katabatic winds studies. The two-dimensional version of that described in Richard et al. (1991) is applied for 
July 12th, 1991 simulations. The aim of this study is to validate the numerical model on the GIMEX situation characterized by ice melting, to compare with other model results, and to investigate whether or not twodimensional simulations are sufficiently reliable to reproduce the structure and time evolution of observed katabatic layers.

\section{The GIMEX experiment}

The GIMEX data were obtained in the western part of Greenland at a latitude of $67^{\circ} \mathrm{N}$ along a line approximately perpendicular to the ice sheet margin. The general set-up of the GIMEX experiment described in Oerlemans and Vugts (1993), is shown in Fig. 1. A total of seven unmanned sites was operated by Utrecht University and the Free University of Amsterdam, numbered according to Fig. 1. Stations 4, 5, 6 and 9 analyzed the katabatic layer and measured the ablation over the ice cap. Site 7, on the other hand, which is situated near the ice-sheet margin, measured the characteristics of the atmospheric flow over the tundra. A captive balloon is used for sounding measurements.

The tundra, characterizing the experimental domain, is blocked between the ice cap in the east and the Atlantic ocean in the west. It is completely ice free during summer. Its average temperature of $10{ }^{\circ} \mathrm{C}$ (Ohmura, 1987) makes of this region the hottest in Greenland. The difference between the physical characteristics of the ice sheet and the tundra induces a thermal gradient. The influence of this gradient on the dynamics of the katabatic flows is significant. To quantify this impact measurements of pressure, temperature, humidity, wind speed and wind direction were made near the ice edge.

The GIMEX experiment lasted 52 days starting June 10 and ending July 31,1991 . The period of 5-24 July, characterized by a stationary and calm synoptic situation (van den Broeke et al., 1994), is selected for the numerical studies. The days of 12,13 and 14 July, marked by a northerly synoptic flow, have been retained for a detailed study because of the important phenom-

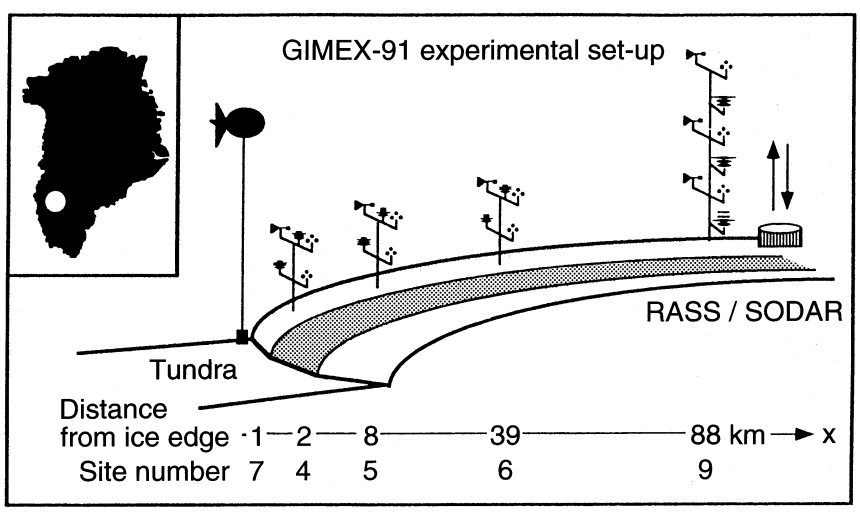

Fig. 1. Locations of five different sites used in the present study on a west-east transect perpendicular to the edge of the Greenland ice sheet, close to Søndre Strømfjord (from Gallée et al., 1995) enon observed and the quality and number of the data obtained. These three days have been simulated and compared to the available GIMEX observations. Since the numerical results of these three days were of little fundamental differences, we have chosen to fully discuss only the results obtained during the 12 July, 1991 situation which was also simulated by Meesters et al. (1994) and Gallée et al. (1995). A comparison with their results will be dealt with later.

\section{Model description}

The SALSA model used is the two-dimensional version of the anelastic hydrostatic model extensively described by Nickerson et al. (1986). The model is written in terrain following sigma coordinates to allow for irregular terrain. The surface layer parametrization follows Louis (1979). In this study, the surface roughness length for momentum is obtained from GIMEX data (Duynkerke and van den Broeke, 1994). A k-L turbulence closure scheme according to Bougeault and André (1986) is used. The cloud and precipitation scheme is based on Berry and Reinhardt (1974a,b). Radiative computations are performed with the ECMWF scheme (Morcrette, 1989). To allow model forcing, a time evolution of lateral boundary conditions is introduced using the relaxation method of Davies (1976). Complete details of the model equations, parametrization of the model physics, initial and boundary conditions can be found in Richard et al. (1989)

The horizontal domain contains 84 grid points (10 km horizontal resolution) covering a distance of approximately $620 \mathrm{~km}$ inland and extending $200 \mathrm{~km}$ out over the ocean. The assumed topography corresponds to the section through west Greenland for which the GIMEX was performed. It is described reasonably well by a parabolic profile as proposed by Oerlemans and van der Veen (1984):

$h_{s}(x)=\left(\frac{2 \tau_{0} x}{\rho_{i} g}\right)^{1 / 2}$

where $\tau_{0}$ represents the yield stress for ice in the approximation of perfect plasticity (assumed to be $100 \mathrm{kPa}), \rho_{i}$ is the density of ice $\left(900 \mathrm{~kg} \mathrm{~m}^{-3}\right), x$ is the distance from ice margin, and $g$ is the gravity constant. Note that the topography has been filtered in order to avoid the generation of $2 \Delta x$ waves.

The vertical grid is composed of 30 levels, with high vertical resolution in the lower layers; $z=0,2,5,10$, $20,40,80,120,200,250,300,350,400,500,600,800$, $1000,1500,2000,2500,3000,4000,5000,6000,7000$, $8000,9000,10000,12000,15000,18000 \mathrm{~m}$. This choice was conditioned by the fact that the thickness of the observed katabatic layer does not generally exceed $300 \mathrm{~m}$. An absorbing layer, in which diffusion increases with height, occupies the ten upper levels and prevents spurious reflection of gravity waves from the top boundary. 


\section{Turbulence scheme}

One of the difficulties faced during the GIMEX simulations is that with the representation of the turbulent exchange in the katabatic layer. The formulation of Bougeault and André (1986), usually used to parametrize the unstable turbulence of thermal origin, was insufficient to compute the stable turbulence generated in katabatic layers. To avoid this problem, we used the empirical formulation of Estournel and Guedalia (1987), which was deduced from experimental data for a nocturnal boundary layer.

In cold and stable atmospheres the boundary layer is the only place where the turbulence exchange is important because of the heating effect (solar radiation) and surface friction. This turbulence has been characterized by the bulk Richardson number $\left(R_{i b}\right)$ expressed as:

$R_{i b}=\frac{g \Delta z \Delta \theta}{\theta U^{2}}$

where $\theta$ is the mean potential temperature, $\Delta \theta$ is the potential temperature difference between the first level and the ground, $\Delta z$ is the first model level, and $U$ is the horizontal wind speed.

To close the turbulent energy equation, the mixing and dissipation length, respectively $l_{k}$ and $l_{\varepsilon}$ have to be specified, as follows:

Under stable surface boundary $\left(R_{i b} \geq R_{c}\right.$, where $R_{c}$ is the transition value of $R_{i b}$ ), the empirical formulation of Estournel and Guedalia (1987) is applied to compute $l_{k}$ and $l \varepsilon$, as:

$l_{k}=l_{\varepsilon}=\left\{\begin{array}{lll}l_{n}\left(1-5 R_{i}\right) & \text { if } \quad \mathrm{Ri}<0164 \\ l_{n}\left(1+41 R_{i}\right) & \text { if } \quad \mathrm{Ri} \geq 0.164\end{array}\right.$

in which the local Richardson number, $R_{i}$ :

$R_{i}=\frac{g}{\theta} \frac{\partial \theta}{\partial z} /\left\{\left(\frac{\partial u}{\partial z}\right)^{2}+\left(\frac{\partial v}{\partial z}\right)^{2}\right\}$

where $u$ and $v$ are the components of horizontal wind.

The neutral mixing length, $l_{n}$ is defined as in Delage (1974):

$l_{n}=\frac{K z}{1+K z / \Lambda}$

where $K$ is the Karman constant and $\Lambda$ is the local Obukhov length defined as:

$\Lambda=410^{-4} \frac{G}{f}$

where $f$ is the Coriolis parameter and $G$ is the geostrophic wind force.

Under unstable boundary conditions $\left(R_{i b} \leq R_{c}\right)$, the formulation of Bougeault and André (1986), is retained.

Starting from these two formulations, we have then come up with an available turbulence parametrization for unstable turbulence exchange over the tundra as well as over the ice cap where the exchange is always stable.

The shift from one formulation to another depends on values taken by $R_{i b}$. Several sensibility tests achieved through the one-dimensional version of the SALSA model on GIMEX data allowed to fix the transition value $R_{c}$ at 0.05 .

\section{Simulation set-up}

The 1991 July 12 simulations make use of the 0000LST, 1200LST, and 2400LST Egedesminde soundings (Fig. 2). These soundings are very similar and only few clouds were actually observed. The model is initialized with the upwind radiosondes data from Egedesminde station and is forced at the boundaries by the 12 hourly observed upwind radiosondes data. The time evolution of the large-scale forcing is incorporated in the model through time dependent boundary conditions updated with the closest upwind sounding data. All simulations were done with the Coriolis parameter.

According to the GIMEX observations (van den Broeke et al., 1994), the wind measured by the three Egedesminde sounding is very weak, indicating that the thermal forcing is also weak. Therefore, the simulations on July 12, 1991 were conducted with zero initial wind speed and zero geostrophic wind.

The three prescribed surface types are sea, tundra and ice which are represented in the model by their morphological and physical properties. Some surface parameters have been used in the present study as in Meesters et al. (1994). Here, we only give (in Table 1) a summary of the simulation parameters, and some elaboration allowing to present correctly the different surface types in the model.

The sea surface temperature is considered ice free, and is fixed during the simulation at a value of $-1.9^{\circ} \mathrm{C}$ as in Gallée et al. (1995).

Over the ice cap, which is situated east of the tundra, the ambient air is in permanent saturation state.
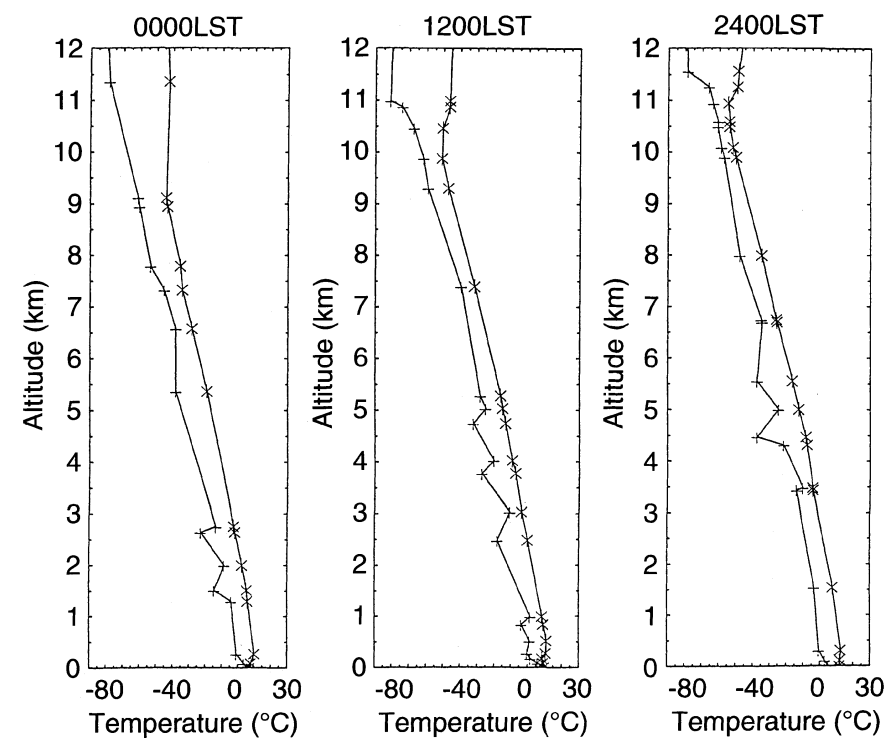

Fig. 2. Temperature and dew point temperature profiles introduced in the model for July 12, 1991 (from 0000 LST to 2400 LST). The stars correspond to the values measured by the Egedesminde station 
Table 1 Surface parameters

\begin{tabular}{|c|c|c|c|c|}
\hline & $\begin{array}{l}\text { Roughness length } \\
\text { (in } \mathrm{cm} \text { ) }\end{array}$ & Emissivity & Albedo & $\begin{array}{l}\text { Thermal conductivity } \\
\text { (in } \mathrm{w} \mathrm{m}^{-1} \mathrm{k}^{-1} \text { ) }\end{array}$ \\
\hline Sea & $\begin{array}{l}0.01 \\
\text { (Arya, 1988) }\end{array}$ & - & - & - \\
\hline Tundra & (GIMEX data) & $\begin{array}{l}0.95 \\
\text { (GIMEX data) }\end{array}$ & $\begin{array}{l}0.2 \\
\text { (GIMEX data) }\end{array}$ & $\begin{array}{l}0.6 \\
\text { (GIMEX data) }\end{array}$ \\
\hline Ice & $\begin{array}{l}0.3 \\
\text { (GIMEX data) }\end{array}$ & $\begin{array}{l}0.97 \\
\text { (Kondo and } \\
\text { Yamazawa, } \\
1986 \text { ) }\end{array}$ & see fig. 3 & $\begin{array}{l}\lambda\left(\rho_{i}\right)=2.0910^{-2}+2.510^{-6} \rho_{i}^{2} \\
\text { with } \rho_{i} \text { the ice density } \\
\text { (Anderson, 1976) }\end{array}$ \\
\hline
\end{tabular}

According to site 9 observations (Henneken et al., 1994), the snow layer on the ice sheet diminishes considerably during summer to a value of a few centimeters. Therefore, the influence of the snow studied by Gallée and Duynkerke (1997) is not taken into account in the present simulations. To estimate the amount of water due to ice melting, an iterative process for the energy budget is applied in the model described in Sect. 6. The initial temperature at the surface is computed from the 0000 LST sounding through a linear interpolation along the topography. If the interpolation result is positive, then $0{ }^{\circ} \mathrm{C}$ temperature is assumed. The albedo imposed on the ice cap surface (Fig. 3) is estimated from GIMEX data (van de Wal et al., 1994). The ice density is computed as in Meesters et al. (1994).

The tundra (Table 1) is considered as a sandy bare soil. Its surface temperature and volumetric moisture content $\eta$ are calculated by solving the diffusion equation for heat and moisture at 6 levels in the first soil meter. The sensible and latent heat fluxes are calculated from an energy balance using a parametrization of the surface boundary layer (Louis, 1979). Initially, the surface temperature is set at $3{ }^{\circ} \mathrm{C}$, as obtained from the Egedesminde sounding at 0000 LST on July 12, 1991. The soil water content $\eta$ is initialized to $\frac{\eta}{\eta}=0.032$ (where $\eta_{s}$ is the saturated moisture content) typical for a dry tundra soil (van den Broeke et al., 1994). At the surface, the temperature and the soil water content are

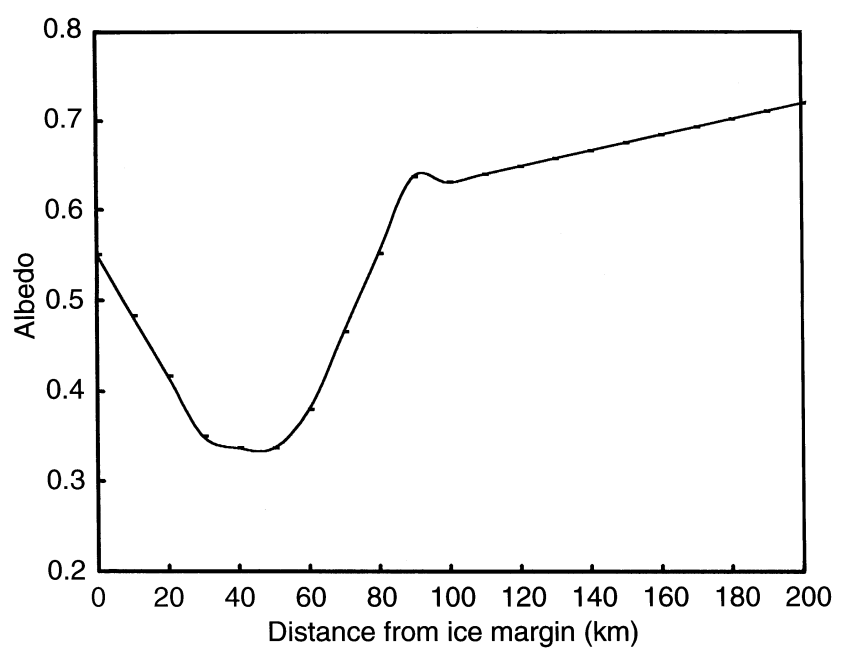

Fig. 3. Surface albedo obtained from GIMEX data (van de Wal and Oerlemans, 1994) determined from the mass and energy budgets. The specific humidity at the surface $q_{g}$ is calculated as $q_{g}=h_{u} q_{s}$, where $q_{s}$ is the saturated specific humidity. In order to have a better representation of the latent heat flux over the tundra, the surface relative humidity scheme of Mc Cumber and Pielke (1981) is replaced by an empirical formulation of Noilhan and Planton (1989).

$$
\begin{cases}h_{u}=0.5\left(1-\cos \left(\pi \frac{\eta_{g}}{\eta_{f c}}\right)\right) & \text { for } \eta \mathrm{g}<\eta \mathrm{fc} \\ h_{u}=1 & \text { for } \eta \mathrm{g} \geq \eta \mathrm{fc}\end{cases}
$$

where $h_{u}$ is the relative humidity of the soil, $\eta_{g}$ is the soil volumic water content, and $\eta_{f c}$ is the field capacity corresponding to a hydraulic conductivity of $0.1 \mathrm{~mm}$ per day.

\section{Simulation of 12 July, 1991 of GIMEX}

After a spin-up time of $6 \mathrm{~h}$, the model is run between 0000 LST and 2400 LST. The results are checked against the measurements taken during the July 12, 1991 at the sites installed along the ice cap and at the operational tundra site. Figure 4 represents the time evolution of the computed potential temperature field $\theta$, which shows important variations over the ice cap and on the tundra.

The analysis of the potential temperature field shows that over the ice sheet slopes, the katabatic flow is fully developed. The cold air present over the high ice sheet progressively moves under the influence of ice cap declivity. The generated katabatic flow is approximately parallel to the terrain contour lines. As the air flows over the ice cap under the action of the gravity force, the terrain slopes are accentuated causing a reinforcement of the wind near the surface. This results in a weakening of the thermal stability and therefore a thickening of the katabatic layer. Indeed, the $\theta$-isolines show a thin and very stable inversion layer for which strength decreases downslope, overlaid by an air layer of weaker stability followed by a stable transition layer to the free atmosphere. The temperature inversion important for the highest surface elevations, is maintained over the ice margin. A moderate turbulence due to the solar radiation and surface friction is induced in boundary layer. This turbulence is mainly responsible for the exchange between the ice cap and the ambient air. To illustrate the importance of this turbulence and the boundary layer 

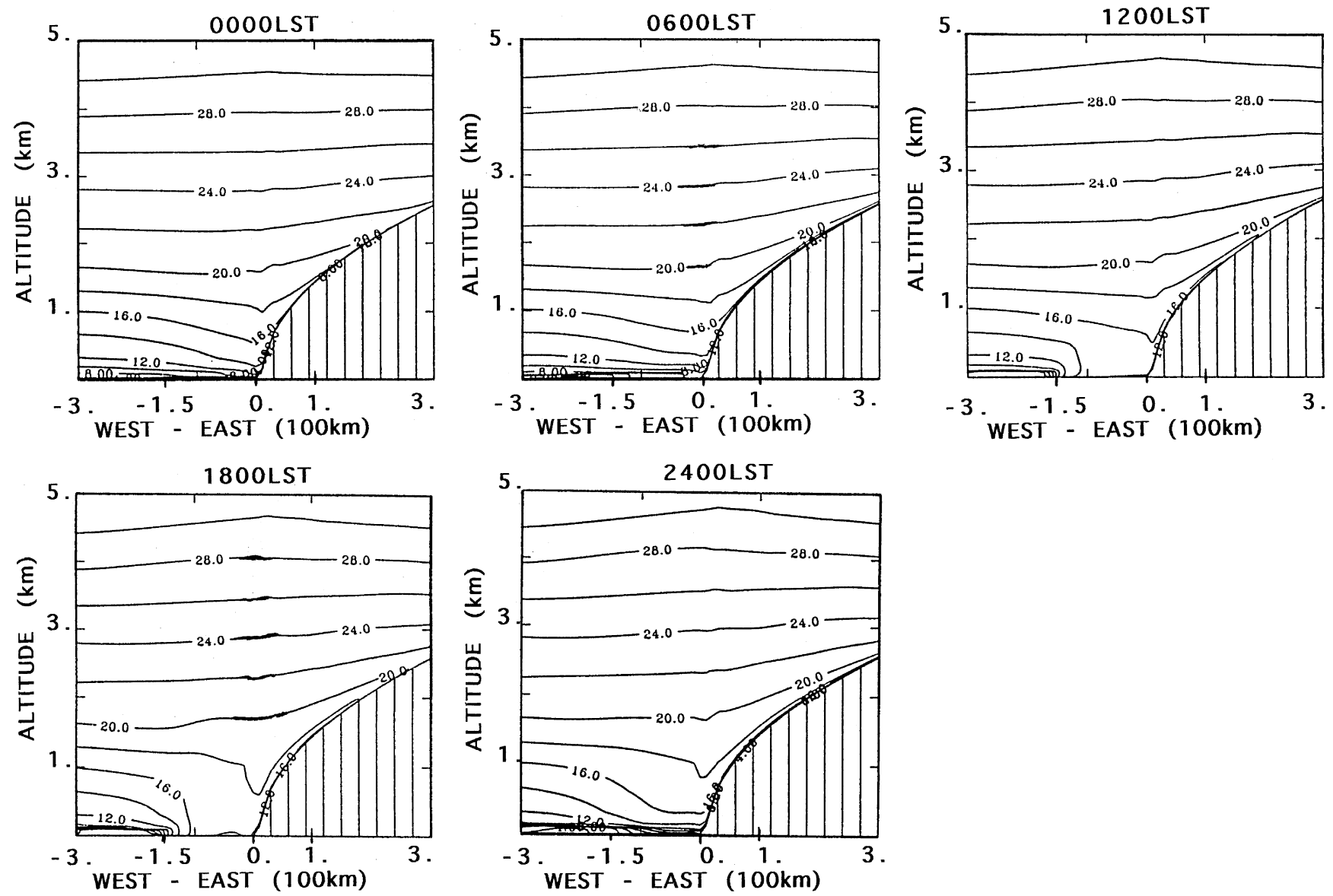

Fig. 4. Potential temperature fields computed on July 12, 1991

thickness over the ice sheet we have shown in Fig. 5 the simulated vertical profiles of turbulent kinetic energy. Near sites 5, 6 and 9 the boundary layer reaches a height of 80 to $150 \mathrm{~m}$, and it persists in time because of the cold weather conditions as referred to in large scale conditions. This is in acceptable agreement with SADAR observations at site 9 (Oerlemans and Vugts, 1993) which indicates a boundary layer depth between 90 and $150 \mathrm{~m}$. Near the ice sheet margin where the slopes are steeper, the katabatic wind speed strengthens while increasing the thermal exchange between the surface and the ambient air. As a result, the boundary layer thickens and reaches a depth of $300 \mathrm{~m}$ near site 4 . According to van den Broeke et al. (1994), the tethered balloon have observed that the thickness of the katabatic layer is typically 100 to $200 \mathrm{~m}$.

Over the tundra, the potential temperature field is marked during day-time by the development of a strong convective boundary layer roughly $1000-1500 \mathrm{~m}$ thick. Indeed, the solar heat flux absorbed by the tundra surface is important during this period of the year (Duynkerke and van den Broeke, 1994). On the left of the tundra at a distance of $150 \mathrm{~km}$ from ice margin, the sea breeze caused by the sea-tundra temperature contrast develops. During night-time, the temperature difference between the tundra and the ice sheet decreases, so that there is no ice breeze effect.
We now examine the $\theta$ field computed at 1800LST where the thermal situation is interesting. Over the flat tundra, the glacier wind of weak intensity mixes up with the hot air already there. The two air masses of different physical properties come to a clash then. The hot air is uplifted as a result of gravity giving way to the cold air to head westward. This phenomenon happens in a rapid way when the tundra temperatures are maximum. The boundary layer rapidly increases from some hundred meters on the ice edge to more than one thousand meters over the tundra. At 1800LST, the estimated depth of this layer is about $1500 \mathrm{~m}$ according to the balloon measurements (Oerlemans and Vugts, 1993; Duynkerke and van den Broeke, 1994).

Over the ice-tundra transition zone, the katabatic flow undergoes a horizontal thermal gradient caused by the differences in physical properties between the ice and the adjacent tundra. The induced wind dominates the katabatic winds imposing on the icy flow thus a deceleration during night-time and an acceleration during day-time. This results in an enhancement of atmospheric circulation favored by a weak synoptic situation. The impact of this circulation is local and is directly reflected on some flow parameters as we can notice in the two computed wind components (Fig. 6, for presentation reasons the topography is omitted) in the contact zone ice-tundra. In the boundary layer over 

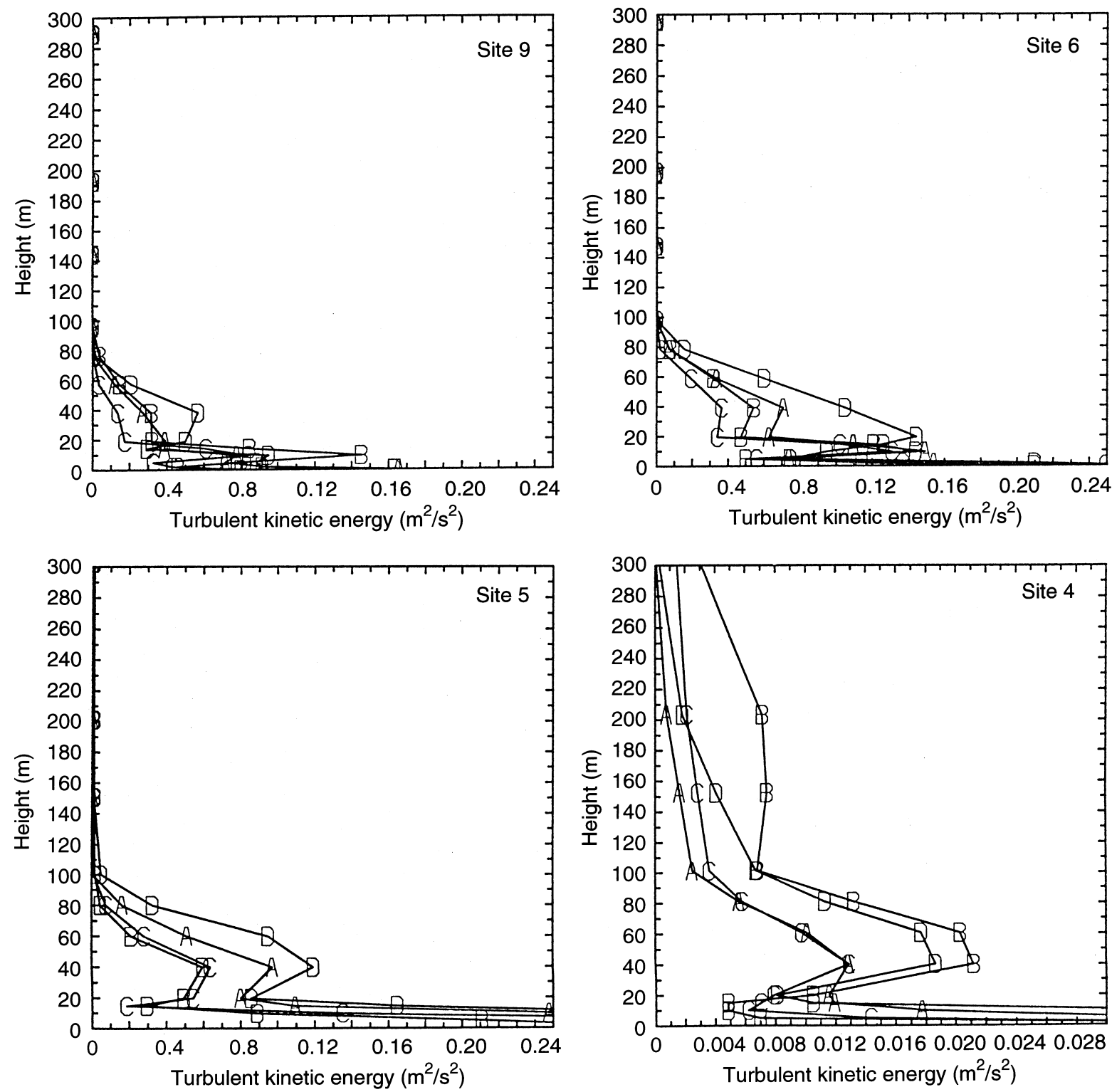

Fig. 5A-D. Time evolution of the vertical profile of the turbulent kinetic energy computed near the experimental sites over the ice cap, on July 12 , A 0600 LST; B 1200 LST; C 1800 LST; and D 2400 LST

the ice sheet, the west-east wind component $(u)$ increases as the air flows down the ice cap slope because of the fact that the buoyancy force dominates (Mahrt, 1982). At $1800 \mathrm{LST}$, it reaches a maximum speed of $8 \mathrm{~ms}^{-1}$ near the ice sheet margin where the slopes are steeper. Outside of the boundary layer, the $u$-component wind speed is very weak close to the zero geostrophic value. The important phenomenon of the downslope wind component is the penetration of glacier flow along the tundra (about $40 \mathrm{~km}$ starting from the ice margin). Further westward, the wind weakens before changing into an inverse current due to the sea-land breeze effect. Near site 9, the simulated wind velocity (not shown) reaches at 1800 LST a maximum of $5.25 \mathrm{~ms}^{-1}$ at a height of $35 \mathrm{~m}$ over the ice sheet. This height remains underestimated when compared to the observations (Oerlemans and Vugts, 1993) and to the simulation results of Gallée et al. (1995). The reason for this disagreement is not explained here. Similarly, the maximum of the south-north transverse wind component $(v)$ coincides with the location of the maximum value of $u$. The $v$-component reaches a maximum of $6 \mathrm{~ms}^{-1}$ which is an overestimated value. Indeed, the computed transverse component is obviously due to the Coriolis effect, which may be too important in twodimensional simulations.

\subsection{Comparison with GIMEX data}

6.1.1 Over the ice cap. The computed and the observed energy budget terms near site 9 (located over the ice sheet, $88 \mathrm{~km}$ far from the ice sheet margin) are illustrated in Fig. 7. The different terms are dominated by the net radiation term. The measured latent and sensible heat fluxes are determined by the correlation 

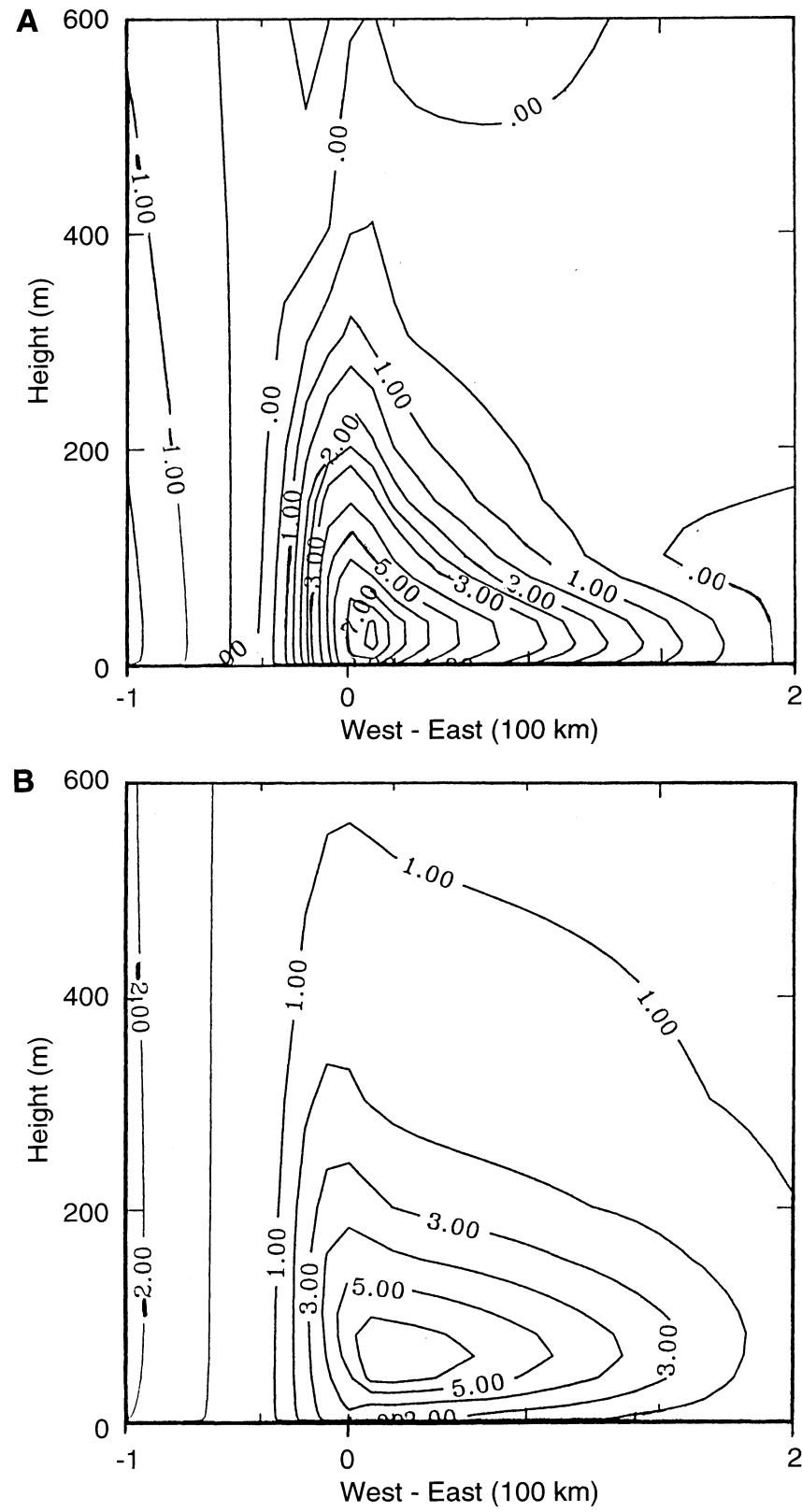

Fig. 6A,B. Wind components computed near the ice edge $(-100 \mathrm{~km}$ from ice edge to $150 \mathrm{~km}$ over the ice cap), on July 12 at 1800 LST, A the east-west component $u$ and the $\mathbf{B}$ north-south component $v$. Notice that the topography has been suppressed from the graphics

method (Henneken et al., 1994) while the simulated fluxes are obtained by solving the energy budget equation at the surface. The heat conductivity flux (not shown) is very weak in the ice layers since the calorific capacity of ice is very important.

The comparison between simulation and the site 9 observations is reasonable for the net radiation. However, we can notice a slight temporal shift. Moreover, the computed maximum energy is overestimated by about $15 \mathrm{Wm}^{-2}$ compared to the observed maximal value. Yet, this discordance is much less than the value $60 \mathrm{Wm}^{-2}$ obtained by Meesters et al. (1994). Concerning the turbulent heat fluxes, the comparison between the simulation without ice/snow process and observations is
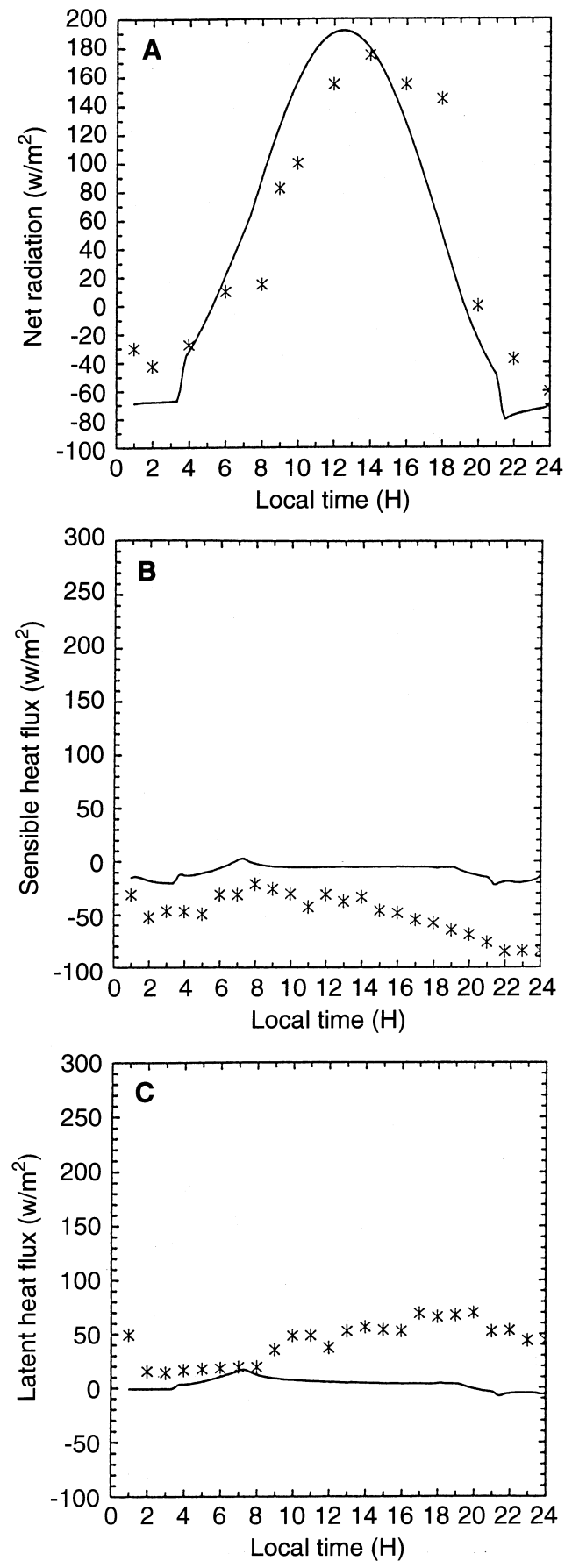

Fig. 7A-C. Time evolution of the measured and computed values of $\mathbf{A}$ the net radiation, $\mathbf{B}$ the sensible heat flux, and $\mathbf{C}$ and the latent heat flux on July 12 from 0000 LST to 2400 LST. The stars correspond to observations at site 9

acceptable. Both in simulation and observations, the sensible heat flux is negative during the whole day indicating that there is a transport of heat from the katabatic layer towards the ice, whereas the latent heat flux is positive indicating that moisture is added to the katabatic layer as a result of evaporation.

Figure 8 illustrates a comparison between simulated and observed flow parameters at site 9. A reasonable agreement is obtained for the $2 \mathrm{~m}$ temperature. Like the 

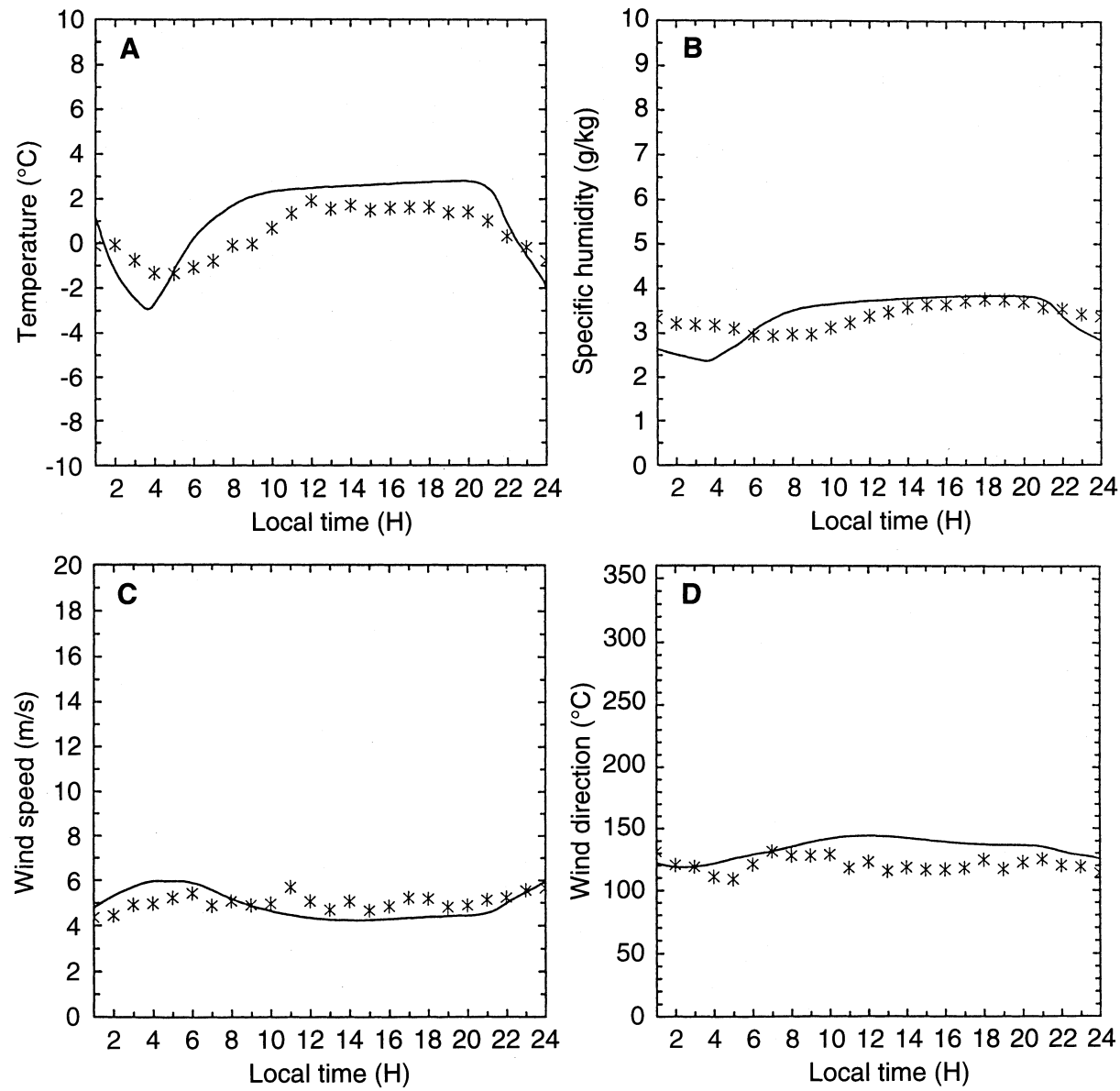

Fig. 8A-D. As in Fig. 7 but for A the $2 \mathrm{~m}$ temperature, $\mathbf{B}$ the $2 \mathrm{~m}$ specific humidity, $\mathbf{C}$ the $8 \mathrm{~m}$ wind speed and $\mathbf{D}$ the $31 \mathrm{~m}$ wind direction on July 12 from 0000 LST to 2400 LST net radiation, the simulated temperature presents a slight temporal shift when compared to the observations. The diurnal amplitude of the observed and the computed temperature attains about $4{ }^{\circ} \mathrm{C}$, with the simulated temperature being slightly colder at night than the observed one. This discordance is a result of the physical process associated with the snow layer present near site 9 (Henneken et al., 1994).

The computed wind and its direction (respectively, at $8 \mathrm{~m}$ and $31 \mathrm{~m}$ ) show a diurnal evolution almost similar to the observations. However, the simulated wind shows a little diurnal variations of $1 \mathrm{~ms}^{-1}$ amplitude whereas the observed wind is nearly stationary with an average of $5 \mathrm{~ms}^{-1}$. These little diurnal variations present in the wind and temperature are very similar to observations made by Wendler et al. (1988) over Antarctic slopes. The wind direction imposed by local topography is quasi-stationary with an average of $130^{\circ} \mathrm{N}$.

Figure 9 shows a comparison between simulation and observations of sites 5 and 6 situated over the ice cap, respectively, 8 and $39 \mathrm{~km}$ far from the ice margin. The agreement between the simulated and observed wind and its direction is good. The wind speed undergoes little diurnal variations because of the constant $\left(0{ }^{\circ} \mathrm{C}\right)$ surface temperature of the area. As at site 9 , the wind direction is SE. The computed temperature presents during day-time a good concordance with the observations, but during night-time it is too low. This discordance in nocturnal temperature is due to the ice/ snow process including refreezing and percolation of melt-water and snow settling (Gallée and Duynkerke, 1997) which is absent from the SALSA model. Concerning the turbulent heat fluxes, there are no observations available at sites 5 and 6 . The simulated sensible heat fluxes (not shown) presents some diurnal variations similar to those obtained for site 9 .

Near site 4 (located on the ice sheet, $2.2 \mathrm{~km}$ distant from the ice edge), the horizontal thermal gradient imposed by the differences in the physical properties of the ice and the tundra is very important. However, this thermal gradient is insufficiently represented in the model due to its course resolution of $10 \mathrm{~km}$. The comparison between simulation and site 4 observations is therefore difficult. Figure 10 shows a tentative to compare the model results for the nearest grid points at the ice margin to site 4 observations. The agreement is not as good as for sites 5 and 6 , except perhaps for the specific humidity at $2 \mathrm{~m}$. The temperature displays small diurnal variations, since the surface temperature in this area is constant, $0{ }^{\circ} \mathrm{C}$. The wind speed shows less agreement. The observations reveal a clear diurnal evolution with a minimum in the morning and a maximum in the afternoon. We expected these differences since observations show that the large amplitude is restricted to a zone which is narrower than the model resolution. The average simulated wind speed close to 

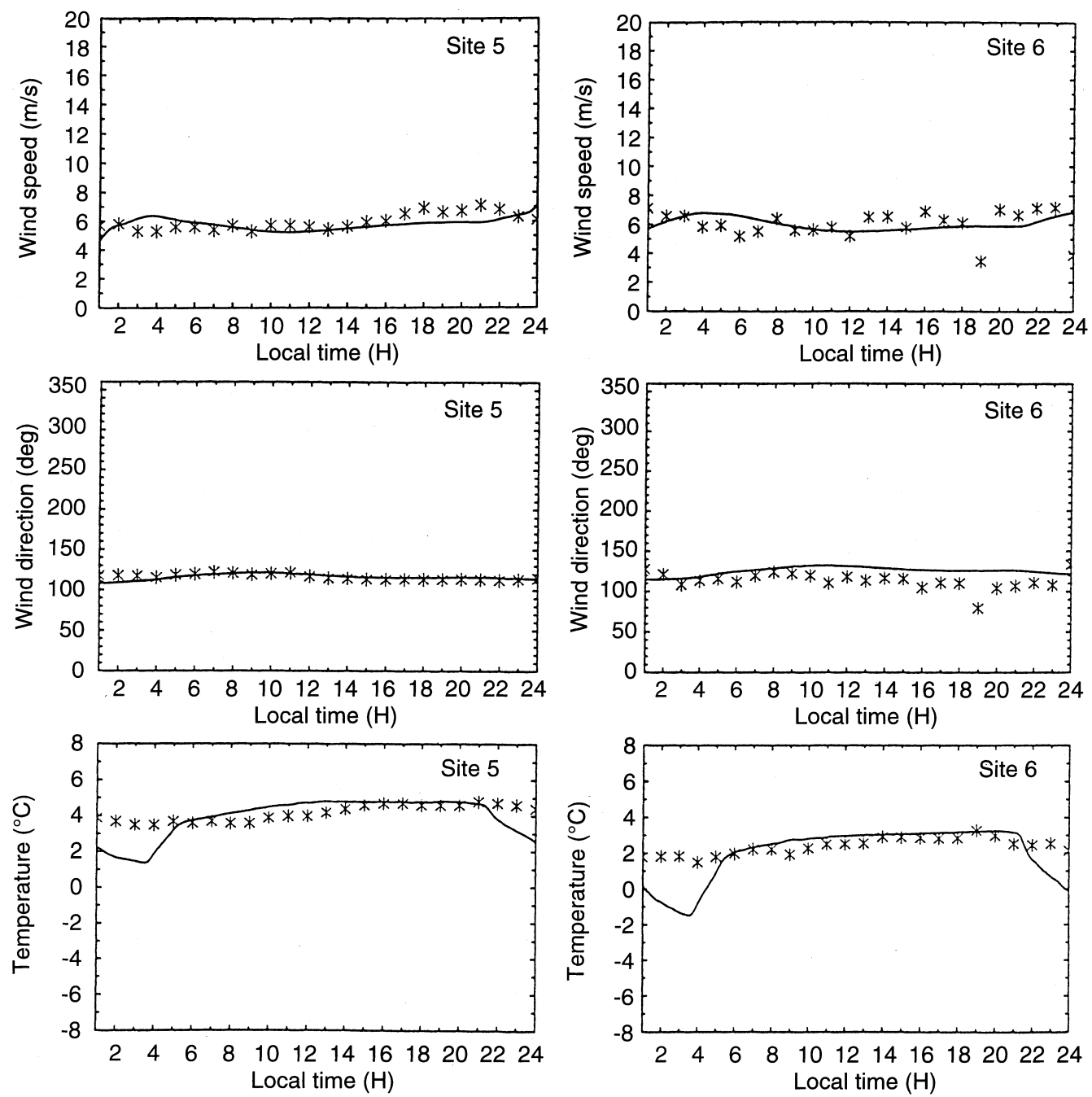

Fig. 9. Time evolution of the computed and measured values of the $6 \mathrm{~m}$ wind speed, the $6 \mathrm{~m}$ wind direction, and the $2 \mathrm{~m}$ temperature on July 12 from 0000 LST to 2400 LST. The stars correspond to observations at site 5 and 6 the ice margin is $8-9 \mathrm{~ms}^{-1}$, and is in reasonable agreement with the observations. Both in simulation and site 4 observations, the wind direction is $\mathrm{SE}$ as at sites 5, 6, and 9, except in the early morning when the observed wind is from the north, the simulated one being constant. Figure 11 shows a comparison between the simulated and observed heat fluxes at site 4 . The agreement is less good for sensible heat flux, but the average calculated sensible heat flux about $-50 \mathrm{Wm}^{-2}$ is comparable to site 4 observations. The latent heat flux remains very weak according to the simulation and observations at site 4 which located in the ablation zone where melting dominates. We can noticed from Figs. 7 and 11 that when the air flows over the ice sheet, the sensible heat flux decreases from site 9 to site 4, whereas the latent heat flux increases. This is in agreement with the decrease in potential temperature and increase in specific humidity.

6.1.2 Over the tundra. The observations over the tundra region were taken at site 7 which is located $0.4 \mathrm{~km}$ away from the ice edge. The measurements obtained at this site are representative of the air flow originating from the ice cap.
The simulated and observed turbulent fluxes are illustrated in Fig. 12. The sensible heat flux shows a clear diurnal evolution which is characteristic for bright days. The tundra absorbs a lot of solar energy because of its weak albedo (0.2). A large part of this energy is transformed into sensible heat leading to important convective movements over the tundra. The maximum energy of $300 \mathrm{Wm}^{-2}$ reached by the simulated sensible heat flux is underestimated by $100 \mathrm{Wm}^{-2}$. This underestimation is due perhaps to the presence of clouds which are not well calculated by the model. The latent heat flux evaluated using Noilhan and Planton (1989)'s method agrees quite well with the observations at site 7 . Its maximum energy is about $120 \mathrm{Wm}^{-2}$. The Bowen ratio reaches a maximum value of 2.5 which is consistent with the observations (Duynkerke and van den Broeke, 1994) and indicates that the soil of the tundra is relatively dry.

The simulated and observed temperature and specific humidity evolution is illustrated in Fig. 13. The temperature has a similar behavior both in simulation and site 7 observations. However, the simulation, in which the hilly tundra topography is not taken, overestimated slightly the temperature. At $1200 \mathrm{LST}$, it is $3{ }^{\circ} \mathrm{C}$ larger. Similar differences were indicated by Meesters et al. 

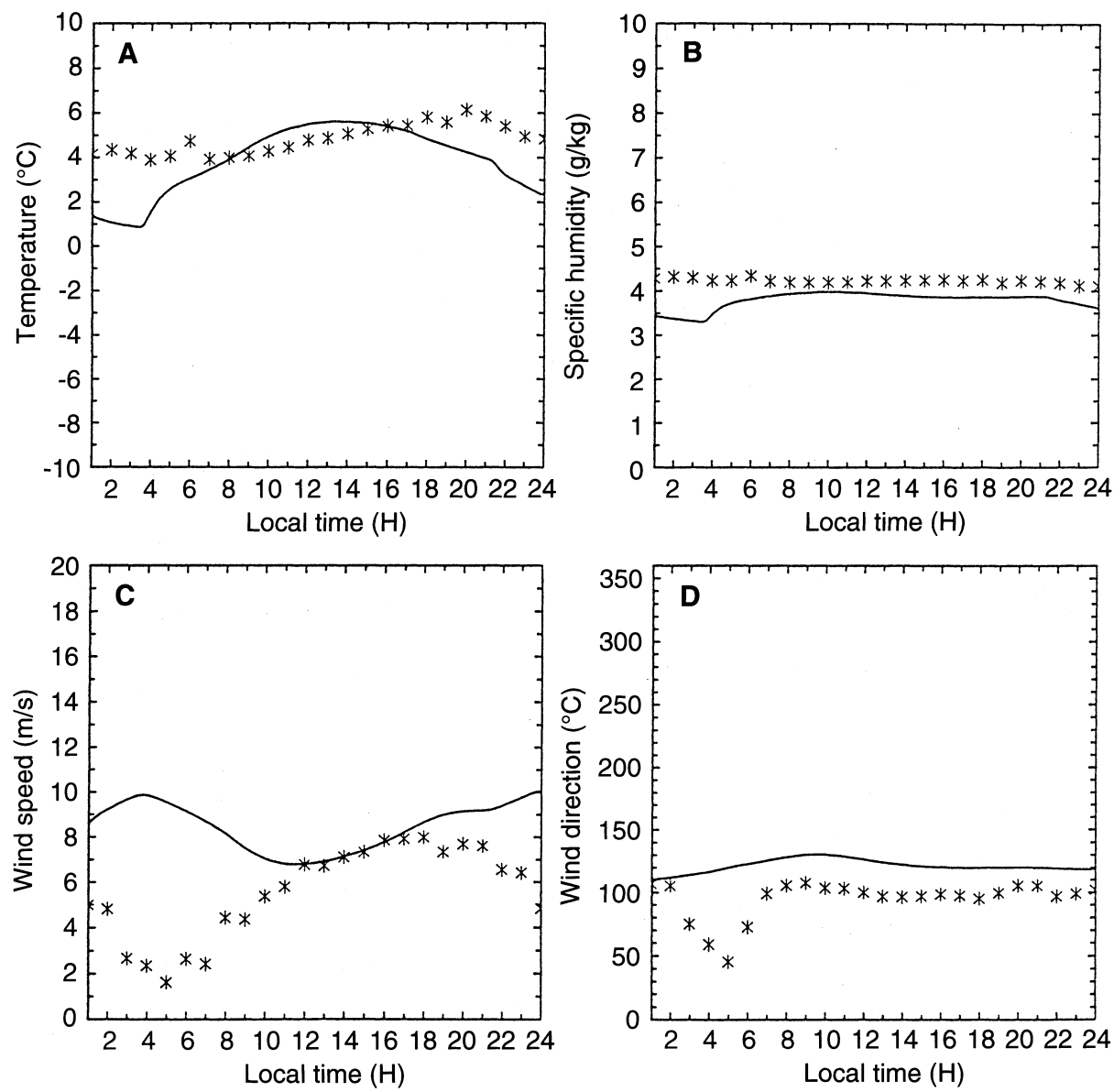

Fig. 10A-D. Time evolution of the computed and measured values of $\mathbf{A}$ the $2 \mathrm{~m}$ temperature, $\mathbf{B}$ the $2 \mathrm{~m}$ specific humidity, $\mathbf{C}$ the $6 \mathrm{~m}$ wind speed and $\mathbf{D}$ the $6 \mathrm{~m}$ wind direction on July 12 from 0000 LST to 2400 LST. The stars correspond to observations at site 4
(1994). A comparison between the simulation and observations for the wind and its direction will be discussed in sect. 7 .

\subsection{Ice ablation}

One of GIMEX objectives was to explore the impact of ice melting on the local atmospheric circulation. To do this, there were measurements of the amount of water produced by ice ablation at sites 4 and 9 . In order to compare model results to these observations, the following scheme has been developed to take into account the melting process.

The energy $\left(Q_{t}\right)$ associated to the process of ablation is computed as the positive residue of the energy balance. We start first by computing the surface temperature. If it is positive, then:

$Q_{t}=R_{\text {net }}-H_{s}-H_{l}-G_{s}$

where $R_{\text {net }}$ denotes the net radiation, $H_{s}$ the sensible heat flux, $H_{l}$ the latent heat flux and $G_{s}$ the sub-surface heat loss.

In the opposite case, one has $Q_{t}=0$.

The amount of melting on a given day $(\Delta \eta$ expressed in $\mathrm{cm} \mathrm{w}$. e), then readily follows from the integration of melting rate with respect to time over the entire day.
$\Delta \eta(c m w . e)=\int_{d a y} \frac{Q_{t}}{\rho_{m} L_{m}} \mathrm{~d} t$

where $L_{m}\left(=3.34105 \mathrm{~J} \mathrm{~kg}^{-1}\right)$ is latent heat of ice, $\rho_{m}$ $\left(=0.001025 \mathrm{~kg} \mathrm{~cm}^{-3}\right)$ is the density of water, and $d t$ is the time step.

The amount of melting is estimated from the simulation results for each model grid point located on the ice cap. The simulated and observed amount of melting is found to be in good agreement (Fig. 14). The computed ablation is consistent with the values of the surface albedo. Its one day variation is very similar to the average variation (van de Wal and Russell, 1994). i.e., the ablation is more important in regions with strong speed where the turbulent exchanges are enhanced (Ohata, 1989, 1991), and become weaker in a very cold zone.

\section{Sensitivity to a specified easterly geostrophic wind}

To investigate the role of heat advection from the tundra, Meesters (1994) performed a simulation on July 12, 1991 using an eastward geostrophic wind of $2.5 \mathrm{~ms}^{-1}$. He realized that the advection of warm air has a weak influence on the ablation zone. To study the numerical model sensibility to large-scale wind forcing Gallée et al. (1995) have simulated the 12-13 July 

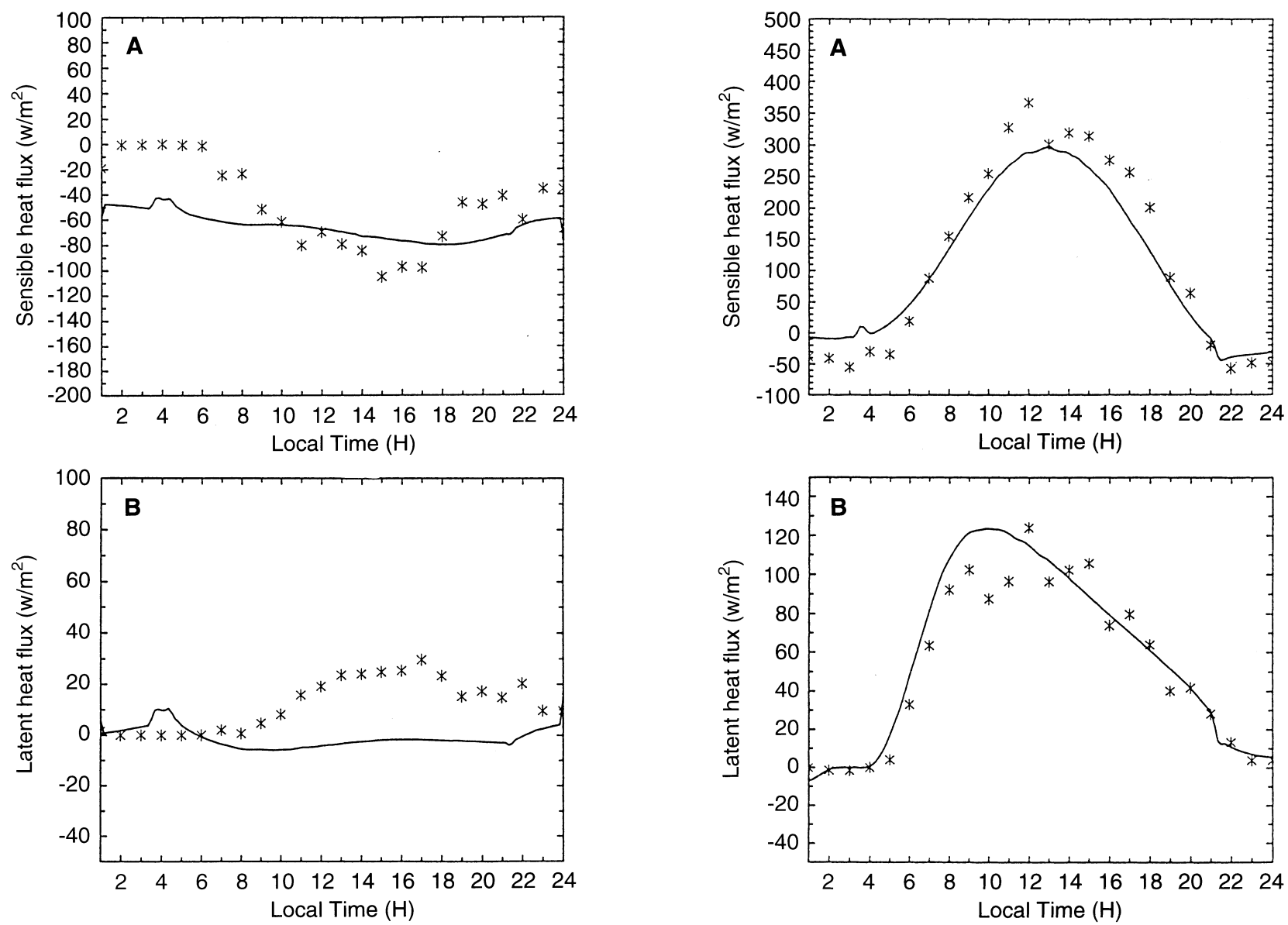

Fig. 11A,B. Time evolution of the computed and measured values of the sensible heat flux A and the B latent heat flux on July 12 from 0000 LST to 2400 LST. The stars correspond to observations at site 4

period. They found that when a zero synoptic-scale forcing is prescribed, the model tends to underestimated flow parameters over the tundra and the ice sheet.

To examine the influence of a geostrophic wind on the development of katabatic winds at the surface, an additional simulation (denoted by $S_{2}$ ) has been conducted under the same conditions of the previous one (denoted by $\left.S_{1}\right)$. As in simulation $\left(S_{1}\right)$, the evolution of the large scale forcing is incorporated in the model through time dependent boundary conditions updated with the closest upwind sounding data. The only difference is the use of an easterly geostrophic wind of $2 \mathrm{~ms}^{-1}$. The value imposed is identical to the real wind speed at $700 \mathrm{hPa}$ measured during GIMEX. To filter out inertial waves, the horizontal wind components have been initialized to their geostrophic components considered constant with height.

The results for simulation $\left(S_{2}\right)$ are considerably different from those of simulation $\left(S_{1}\right)$. The horizontal wind components computed by simulation $\left(S_{2}\right)$ are illustrated in Fig. 15. We notice that the introduction of an easterly geostrophic forcing modifies largely the structure and intensity of the winds in the ice edge zone. Above the higher part of the ice sheet where the $u$ component remains almost zero for simulation $\left(S_{1}\right)$, an easterly wind is present in the new simulation. The

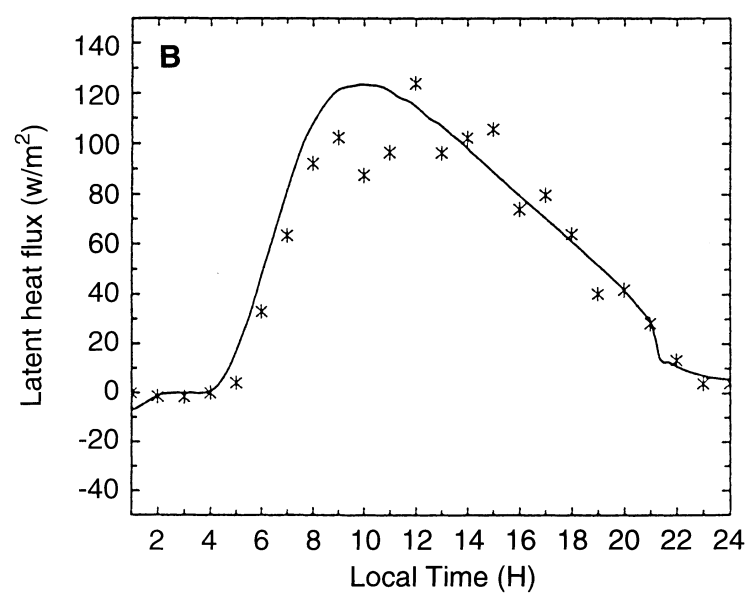

Fig. 12A,B. As in Fig. 11 but for site 7

maximum of this wind is found above the lee slope, reaching $-10 \mathrm{~ms}^{-1}$. As a result of simulation $\left(S_{2}\right)$ the glacier wind flows over the tundra, extending over some $40 \mathrm{~km}$ from the ice margin. After $18 \mathrm{~h}$ of integration a weak west wind zone develops in altitude. Concerning the $v$-component, the differences are also important between the two simulations. In the present simulation, the $v$-component which is produced by the Coriolis effect, is amplified in altitude. Above the ice sheet the wind has a strong northward component, exceeding $8 \mathrm{~ms}^{-1}$ above the ablation zone.

Figure 16 shows the diurnal evolution of wind speed and its direction for simulations $\left(S_{1}\right)$ and $\left(S_{2}\right)$, and observations at site 7 . We noticed that the inclusion of an easterly geostrophic wind of $2 \mathrm{~ms}^{-1}$ strongly influences the wind over the tundra. In the absence of any geostrophic effect (simulation $S_{1}$ ), the simulated wind speed at site 7 reaches approximately $1.5 \mathrm{~ms}^{-1}$. An initial $2 \mathrm{~ms}^{-1}$ easterly wind acts to amplify the development of wind speed during the day (Bechtold et al., 1991), it reaches approximately $3.5 \mathrm{~ms}^{-1}$. The geostrophic wind leads to a similar wind development as it is observed at site 7, i.e. a wind speed between 2 and $3.5 \mathrm{~ms}^{-1}$, reaching its maximum in the afternoon. As for the wind direction, it is quasi-stationary in the run without geostrophic forcing, around $110^{\circ} \mathrm{N}$. For the run with easterly geostrophic forcing, the wind direction is rather northerly as in site 7 observations. 

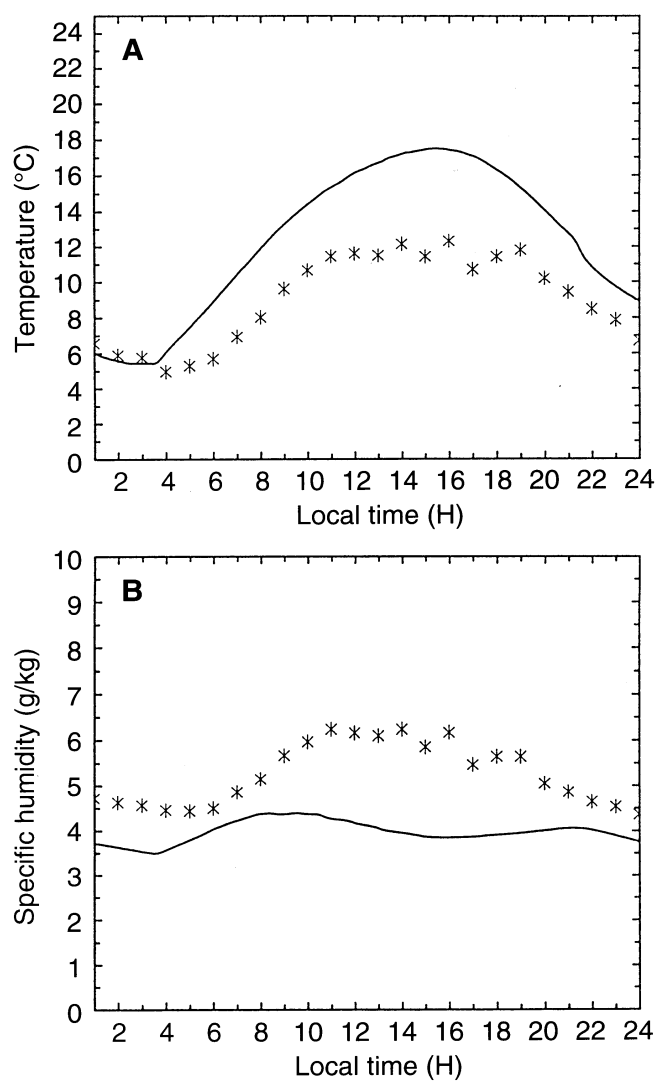

Fig. 13A,B. Time evolution of the measured and computed values of A the $2 \mathrm{~m}$ temperature and $\mathbf{B}$ the $2 \mathrm{~m}$ specific humidity on July 12 from 0000 LST to 2400 LST. The stars correspond to observations at site 7

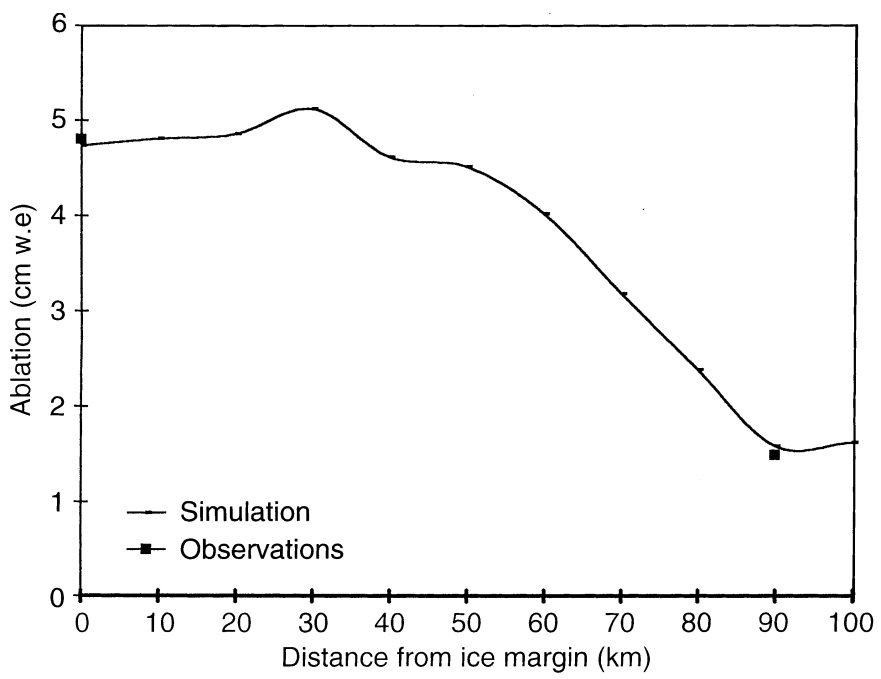

Fig. 14. Melting profile as a function of the distance of model grid points along the GIMEX transect. The stars correspond to the measured values

\section{Conclusion}

Two-dimensional numerical simulations were performed for one GIMEX event (July 12, 1991) which is
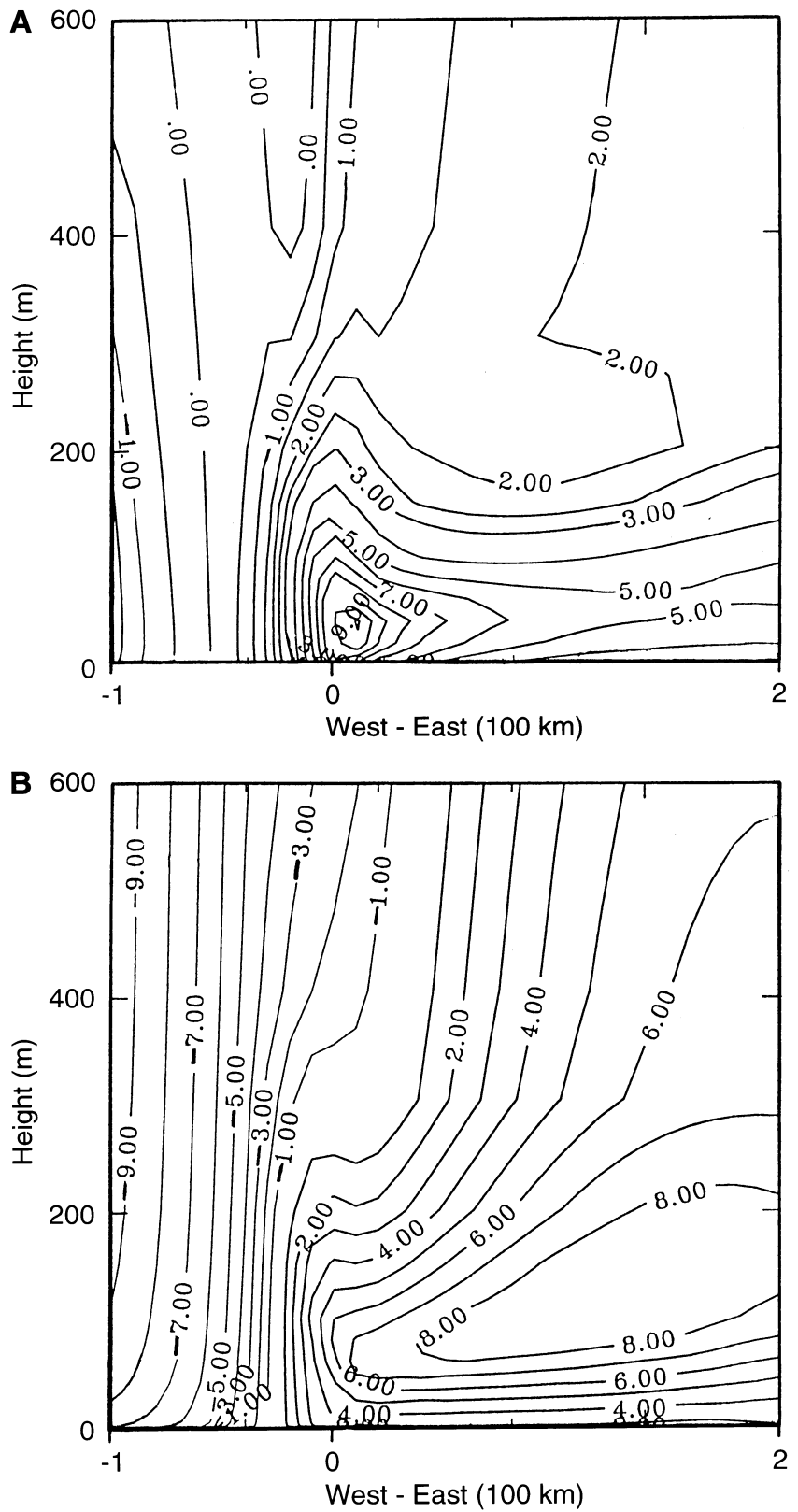

Fig. 15A,B. As in Fig. 6 but for simulation $\left(S_{2}\right)$

characterized by a calm and stationary large-scale meteorological situation. The time evolution of the large-scale flow was incorporated in the model through time-dependent boundary conditions that were updated using soundings from Egedesminde station.

In general, the model is able to compute katabatic flows observed on the transect westward of Greenland.

The introduction of the stable turbulence parametrization of Estournel and Guedalia (1987) allowed good representions of the turbulent exchange over the ice sheet. The model simulated the katabatic layer near site 9, where cold air dominates, as well as at the ice edge (site 4) where the turbulent exchange is more developed. The depth of the katabatic layer $(80 \mathrm{~m}$ at site 9) increases as the cold air flows over the ice cap towards the tundra. It reaches $300 \mathrm{~m}$ at site 4 which is 

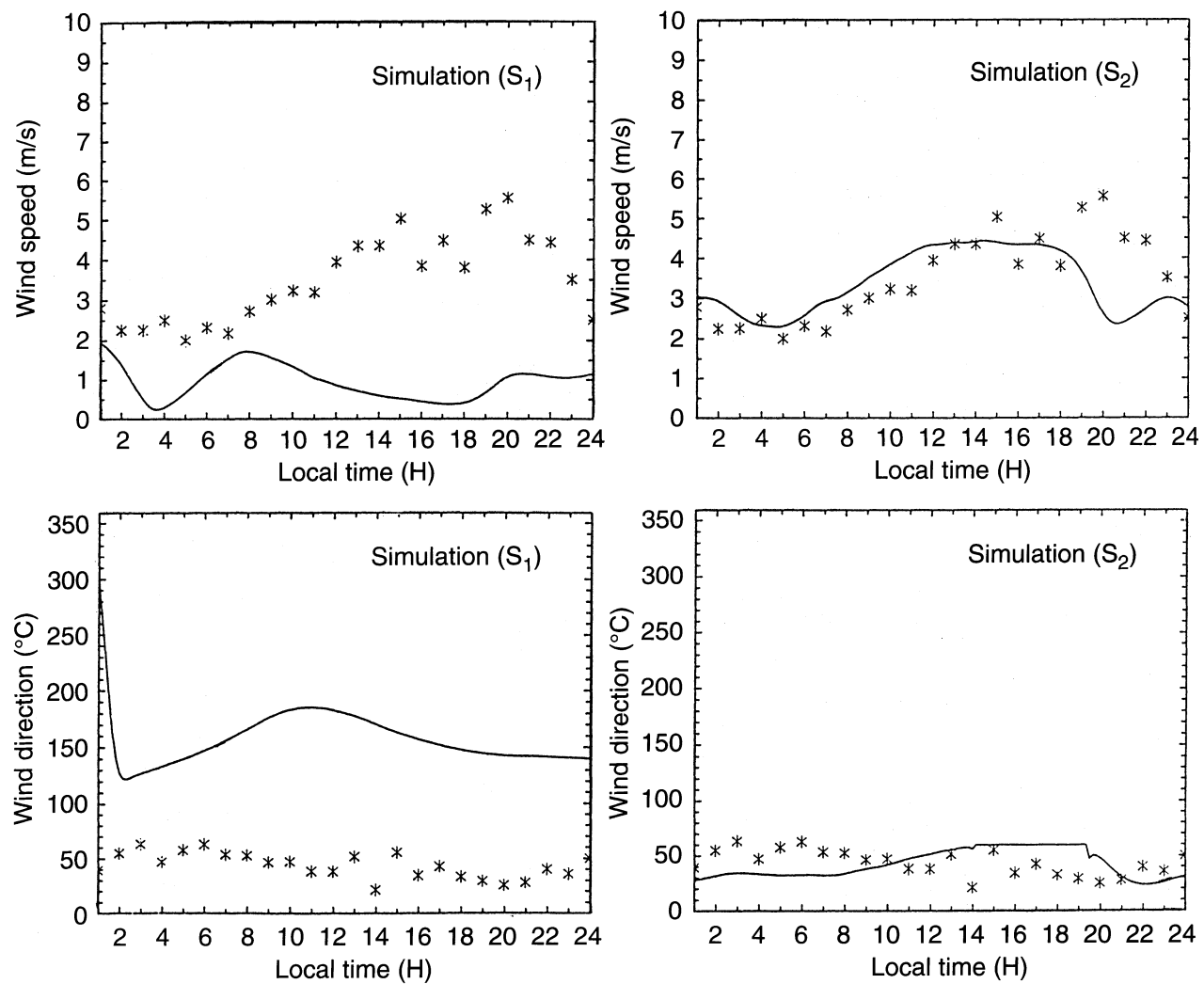

Fig. 16. Time evolution of the computed and measured values of the $6 \mathrm{~m}$ wind speed and the $6 \mathrm{~m}$ wind direction, resulting from the simulation $\left(S_{1}\right)$ without geostrophic forcing, and the simulation $\left(S_{2}\right)$ with a specific easterly geostrophic wind of $2 \mathrm{~ms}^{-1}$. The stars correspond to observations at site 7

concordant with the observations(van den Broeke et al., 1994).

Near site 9, the concordance between the simulation and the observations is reasonable for all parameters (temperature, humidity, wind speed, wind direction, and heat fluxes) except for the net radiation which shows some unclear differences which are also present in the results of Meesters et al. (1994).

As for sites 5 and 6 , the agreement between the simulations without geostrophic forcing and observations is good for wind and its direction. The model reproduces the observed temperature, except at night where it too lower. This discordance will be explained by the ice/snow process absent of the model.

Near the ice edge, the katabatic flow is influenced by the thermal gradient imposed by the warm tundra. This thermal forcing is very local and badly represented in the model. The agreement between the simulation and the site 4 observations is not good. Among reasons for this discordance, we can argue the large course horizontal resolution of $10 \mathrm{~km}$ used during the simulation, and the misrepresentation of the tundra topography and the local ice sheet slopes in the model.

We have also computed the ice melting along the ice cap. The amount of melting is strongly correlated with the value of the albedo of the surface. We have also noticed that the ablation occurs favorably in regions with strong wind speed.

The tundra, having a surface albedo of 0.2 , absorbs an important amount of solar energy. Most of this energy is transformed into sensible and latent heat fluxes leading to convective movements in the boundary layer.
The height of this mixing layer (about 1000-1500 m) is in agreement with the observations. The sensible heat flux values of $300 \mathrm{Wm}^{-2}$ expresses the importance of convective movements generated over the tundra. The diagnostic parametrization of Noilhan and Planton (1989) for the surface relative humidity allowed to accurately simulate the latent heat flux measured over the tundra.

Finally, the model results proved to be sensible to the geostrophic effect. This sensibility is obvious over the tundra. An easterly geostrophic wind of $2 \mathrm{~ms}^{-1}$ permitted to improve the simulated diurnal evolution of the wind and its direction. This result agrees with Gallée et al. (1995). In the katabatic layer over the ice sheet, the comparison between simulations with and without the imposed geostrophic effect, showed only minor differences with the observations.

The present simulations carried out for the GIMEX experiment allowed to validate the SALSA model for real situations of katabatic winds. The results showed that two-dimensional simulations are a useful tool to represent the katabatic flows observed in the westward transect of Greenland.

Acknowledgements. The GIMEX experiment was made possible by the participation of the Institute of Earth Sciences, Amsterdam and Institute for Marine and Atmospheric Sciences, Utrecht. The author wishes to thank the GIMEX collaborators, Prof. R. Rosset, Dr P. Mascart, Dr. P. Bechtold, Prof. G. Schayes, Dr. H. Gallée, Dr. O. Fontaine de Ghélin, Dr. van den Broeke, and Prof. Z. Hachoum. The computer simulations were carried out with the support and assistance of CCVR, Palaiseau, France.

Topical Editor J.-P. Duvel thanks R. D. Bornstein and another referee for their help in evaluating this paper. 


\section{References}

Anderson, E. A., A point energy and mass balance model of snow cover, NOAA Tech. Rep. NWS, 19, 150p., US Department of Commerce, Washington, D.C., 1976.

Arya, S. P., Introduction to micrometeorology, Academic Press, San Diego, 1988.

Bechtold, P., J. P. Pinty, and P. Mascart, A numerical investigation of the influence of large-scale winds on sea breeze and inland breeze type circulations, J. Appl. Meteorol, 30, 1268-1279, 1991.

Berry, E. X., and R. L. Reinhardt, An analysis of cloud drop growth by collection: Part II. single initial distributions, J. Atmos. Sci., 31, 1825-1831, 1974a.

Berry, E. X., and R. L. Reinhardt, An analysis of cloud drop growth by collection: Part III. accretion and self-collection, J. Atmos. Sci., 31, 2118-2126, 1974b.

Bougeault P., and J. C. André, On the stability of the third - order turbulence closure for the modeling of the stratocumulus topped boundary layer, J. Atmos. Sci., 43, 1574-1581, 1986.

Davies, H. C., A lateral boundary formulation for multi-level prediction models, Q. J. R. Meteorol Soc., 102, 405-418, 1976.

Delage, Y, A numerical study of the nocturnal atmospheric boundary layer, Q. J. R. Meteorol Soc., 100, 351-364, 1974.

Duynkerke, P. G., and M. R., van den Broeke, Surface energy balance and katabatic flow over glacier and tundra during GIMEX-91, Global Planet. Change, 9, 17-28, 1994.

Elkhalfi, A., M. Georgelin, and E. Richard, Two-dimensional simulations of mountains waves observed during the PYREX Experiment, Mon. Weather Rev., 123, 2149-2164, 1995.

Estournel, C., and D. Guedalia, A new parametrization of eddy diffusivities for nocturnal boundary-layer modeling, BoundaryLayer Meteorol., 39, 191-203, 1987.

Gallée, H., O. Fontaine de Ghélin, and M. R., van den Broeke, Simulation of Atmospheric circulation during the GIMEX 91 Experiment using a meso- $\gamma$ primitive equation model, J. Clim., 8, 2843-2859, 1995.

Gallée, H., and P.G Duynkerke, Air-snow interactions and the surface energy and mass balance over the melting zone of west Greenland during the Greenland Ice Margin Experiment. J. Geophys Res., 102, 13813-13824, 1997.

Georgelin, M., E. Richard, M. Petitdidier, and A. Druilhet, Impact of subgrid-scale orography parametrization on the simulation of orographic flows, Mon. Weather Rev., 122, 1509-1522, 1994.

Henneken, E. A. C., N. J. Bink, H. F. Vugts, F. Cannemeijer, and A. G. C. A. Meesters, A case study of the daily energy balance near the equilibrium line on the Greenland ice sheet, Global Planet. Change, 9, 29-38, 1994.

Kondo, J., and H. Yamazawa, Measurement of snow surface emissivity, Boundary-Layer Meteorol., 34, 415-416, 1986.

Louis, J. F., A parametric model of vertical eddy fluxes in the atmosphere, Boundary-Layer Meteorol., 17, 187-202, 1979.

Mahrt, L., Momentum balance of gravity flows, J. Atmos. Sci., 39, 2701-2711, 1982.
Mc Cumber, M. C., and R. A., Pielke, Simulation of the effects of surface fluxes of heat and moisture in a mesoscale numerical model. Part I: soil layer, J. Geophys. Res., 86, 9929-9938, 1981.

Meesters, A. G. C. A., A. A. C. Henneken, N. J. Bink, H. F. Vugts, and F. Cannemeijer, Simulation of the atmospheric circulation near the Greenland ice sheet margin, Global Planet. Change, 9, 53-67, 1994.

Meesters, A., Dependence of the energy balance of the Greenland ice sheet on climate change: Influence of katabatic wind and tundra, Q. J. R. Meteorol. Soc., 120, 491-517, 1994.

Morcrette, J. J., Impact of changes to the radiation transfer parametrization plus cloud optical proprieties in the ECMWF model, Mon. Weather Rev., 118, 847-873, 1989.

Nickerson, E. C., E. Richard, R. Rosset, and D. R. Smith, The numerical simulation of clouds rain, and airflow over the Vosges and Black Forest mountains: A meso- $\beta$ model with parametrized microphysics, Mon. Weather Rev., 114, 398-414, 1986.

Noilhan, J., and S., Planton, A simple parametrization of land surface processes for meteorological models, Mon. Weather Rev., 117, 536-549, 1989.

Oerlemans, J., and M. R, van der Veen, Ice sheet and climate, Reidel, Dordrecht, 217 p, 1984.

Oerlemans, J., and H., Vugts, A meteorological experiment in the ablation zone of the Greenland Ice sheet, Bull. Am. Meteorol. Soc., 74 (3), 355-365, 1993.

Ohata, T., Katabatic wind on melting snow and ice surfaces (I). Stationary glacier wind on a large maritime glacier, J. Meteorol. Soc. Jap., 67, 99-112, 1989.

Ohata, T., The effect of glacier wind on local climate turbulent heat fluxes and ablation, Z. Gletscherkd. Glazialgeol., 25, 49-68, 1991.

Ohmura, A., New temperature distribution maps for Greenland, $Z$. Gletscherkd. Glazialgeol., 23, 1-45, 1987.

Richard, E., P. Mascart, and E. C. Nickerson, The role of surface friction in downslope windstorm. J. Appl. Meteorol., 28, 241251, 1989.

van de Wal, R. S. W., and A. J. Russell, A comparison of energy balance calculations measured ablation and meltwater runoff near Søndre Strømfjord, West Greenland, Global Planet. Change, 9, 29-38, 1994.

van de Wal, R. S. W., and J. Oerlemans, An energy balance model for the Greenland ice sheet, Global Planet. Change, 9, 115-131, 1994.

van den Broeke, M. R., P. G. Duynkerke, and J. Oerlemans, The observed katabatic flow at the edge of the Greenland ice sheet during GIMEX - 91, Global Planet. Change, 9, 3-15, 1994.

Wendler, G., Y. Kodama, and A. Poggi, Katabatic wind in Adélie Land, Antarctic J. U. S., 18, 236-238, 1983.

Wendler, G., Ishikawa, N., and Kodamo, Y., The heat balance of the icy slope of Adélie land, eastern Antarctica, J. Appl. Meteorol., 27, 52-65, 1988. 